\title{
Funk e McDonald's: disputas simbólicas e negociações de valor na campanha publicitária Novinhos Cheddar ${ }^{1}$
}

\section{Funk and McDonald's: symbolic disputes and value negotiation in the advertising campaign "Novinhos Cheddar"}

Simone Evangelista Cunha ${ }^{2}$

Beatriz Polivanov ${ }^{3}$

Resumo: $O$ artigo investiga negociações de valor relacionadas à apropriação de uma música do gênero musical funk pela marca de fast food McDonald's em sua campanha intitulada \#Novinhos Cheddar. Através de análise de comentários postados na página do vídeo "Os \#NovinhosCheddar estão no McDonald's. De novo!" no YouTube, problematizamos relações entre consumo, identidade (pessoal e de marca) e disputas de valor na cultura digital, entendendo que essas três esferas operam de forma conjunta. Concluímos que grande parte do público demonstrou ter aprovado a campanha, ressaltando que a estratégia de aproximação com expressões culturais populares/periféricas pode ser profícua. Entretanto, destacamos que essa aproximação não se dá de forma isenta, uma vez que diversos elementos que reforçam a conexão entre funk e periferia foram sumariamente apagados na campanha da multinacional.

Palavras-chave: funk; gêneros musicais periféricos; comunicação e consumo; identidade; YouTube.

1 Uma primeira versão deste trabalho foi apresentada no $6^{\circ}$ Congresso Internacional em Comunicação e Consumo (Comunicon), realizado em 2016 na ESPM de São Paulo. Agradecemos às professoras Patrícia Burrowes e Gisela Castro pelas valiosas contribuições, que acrescentamos às discussões promovidas neste artigo.

2 Universidade Federal Fluminense. Niterói, RJ, Brasil. E-mail: simoneevangelista01@gmail. com

3 Universidade Federal Fluminense. Niterói, RJ, Brasil. E-mail: beatrizpolivanov@id.uff.br 
Abstract: The paper discusses negotiations of value related to the appropriation of a Brazilian funk song by the fast food brand MacDonald's in its campaign entitled \#Novinhos Cheddar. By means of the analysis of comments posted on the video page "The \#NovinhosCheddar are at McDonald's. Again!" on YouTube, we problematize relationships between consumption, identity (personal and brand related) and value disputes in digital culture, understanding that these three spheres operate together. We conclude that a major part of the public has demonstrated its approval of the campaign, emphasizing that the strategy of approaching popular / peripheral cultural expressions can be profitable. However, we highlight that this approach does not take place without tensions, since several elements that reinforce the connection between funk and the periphery were summarily erased in the multinational's campaign.

Keywords: funk; peripheral musical genres; communication and consumption; identity; YouTube. 


\section{Introdução}

Em outubro de 2015, uma das marcas mais conhecidas do mundo, McDonald's, lançou um vídeo no YouTube divulgando seus novos produtos - sanduíches e batata frita com camadas de queijo tipo cheddar. Tal vídeo fazia parte de uma campanha publicitária multimidiática que tinha como alvo o público jovem brasileiro e trazia uma peculiaridade: apresentava uma música de funk remixada para a campanha. Mais especificamente, utilizava como mote principal uma paródia de "As novinhas tão sensacional”, música de MC Romântico e DJ Bambam lançada pela primeira vez em 2013 e relançada no início de 2014 em uma versão mais "leve", sem os palavrões e outras palavras de baixo calão da letra original.

Com a paródia, o McDonald's aproveitou a popularidade de "As novinhas tão sensacional”, cujo clipe oficial (MC ROMÂNTICO, 2014) somava, em abril de 2017, mais de 29 milhões de visualizações na plataforma de vídeos, e transformou a letra erotizada da música, classificada como "funk putaria" ${ }^{4}$, em uma ode ao prazer proporcionado pelo consumo de produtos alimentícios de fast food. Uma dupla apropriação, considerando a versão "proibida" (responsável pelo sucesso inicial em bailes funk) e a versão "oficial” (sem palavrões) da música. Devido ao sucesso de público, a marca decidiu fazer uma nova versão da campanha, entre agosto e setembro de 2016. Com pequenas alterações na letra e na melodia, a campanha \#NovinhosCheddar de 2016 (OS \#NOVINHOSCHEDDAR..., 2016) teve audiência 10 vezes maior que a primeira versão e a mais expressiva entre todos os vídeos disponibilizados pelo McDonald's Brasil em seu canal.

Mesmo em se tratando de uma marca com público bastante amplo, incluindo camadas populares, a apropriação do funk na peça publicitária se mostrou uma aposta potencialmente arriscada. Em 2013, a montadora Mercedes-Benz utilizou a música "Passinho do Volante", cujo videoclipe foi um dos mais vistos pelo público brasileiro naquele ano,

4 O funk denominado "putaria” é um subgênero do funk caracterizado por letras que abordam temas sensuais, muitas vezes de forma explícita. 
para promover o lançamento do carro Mercedes-Benz Classe A. Veiculado exclusivamente no YouTube, o vídeo apresentava apenas o refrão do funk - inalterado - como trilha sonora. A iniciativa gerou polêmica e foi noticiada em veículos de mídia especializados em marketing (TURLAO, 2013) e no setor automotivo por conta da associação "inusitada" entre uma marca relacionada ao mercado de luxo e o gênero. Apesar da letra sem palavras de baixo calão ou duplo sentido (diferentemente de "As novinha tão sensacional"), o uso da música teve alto índice de rejeição, o que levou a montadora a retirar o vídeo de seu canal.

Enquanto gênero musical "periférico", o funk ainda carrega estigmas sociais associados a ideias de baixa cultura, violência, vulgaridade (HERSCHMANN, 2000; FACINA, 2010; LOPES, 2010), entre outros. Por outro lado, conforme mostra Evangelista Cunha (2014), artistas e produtores culturais vinculados ao funk têm se apropriado intensamente das mídias sociais para divulgar suas músicas, inclusive por meio de videoclipes cada vez mais elaborados, o que tem contribuído para a popularização do gênero e, ao mesmo tempo, para o aumento de críticas e mobilizações de haters.

A partir desse contexto, nosso objetivo é compreender de que formas se dá a vinculação entre a campanha Novinhos Cheddar do McDonald's e o funk nas mídias digitais, nas quais a relação entre consumo e identidade se torna ainda mais visível por meio de diferentes elementos e ambientes que possibilitam a expressão de identidades. Em um momento no qual identidades de marcas e sujeitos provocam intensos debates na contemporaneidade, o objeto de estudo deste artigo nos parece particularmente interessante para compreender os diversos processos sociais e culturais imbricados nas apropriações de gêneros musicais periféricos.

Desta forma, a proposta deste trabalho, de cunho exploratório, é identificar disputas simbólicas envolvidas na relação entre funk e publicidade. Argumentamos que essa equação é marcada por uma tensão

5 Ao atribuir o termo "periférico" ao funk carioca, defendemos que o gênero se configura como um importante mediador para questões relacionadas a discussões sobre periferia, como desigualdades sociais e exclusões territoriais, argumento desenvolvido em trabalhos anteriores (PEREIRA DE SÁ e EVANGELISTA CUNHA, 2014; EVANGELISTA CUNHA, 2014). 
dialética que envolve, entre outros aspectos, negociações de sentido por meio de uma "higienização" do gênero, tornando-o mais "palatável" para determinados públicos. Como mostra o exemplo da Mercedes-Benz, a referência a camadas populares, ainda associadas a uma eterna "luta pela sobrevivência" em ambientes marcados pela "carência material" (BARROS e ROCHA, 2007, p. 2) que impediria o consumo além da subsistência, está distante da unanimidade. Para além das diferenças entre os públicos da montadora e do McDonald's, argumentamos que a cadeia de fast food utilizou uma série de estratégias para neutralizar possíveis críticas e reforçar os vínculos com os fãs da marca.

Para isso, faremos primeiramente um breve histórico sobre o funk de modo a contextualizar o objeto de pesquisa para, em seguida, discutirmos sobre as relações entre consumo e identidade, com especial destaque para esse processo na cultura digital. Por fim, apresentaremos uma análise de comentários do público relacionados especificamente à música da campanha \#NovinhosCheddar de 2016. A amostra foi selecionada a partir do vídeo disponibilizado no canal do McDonald's no YouTube.

\section{Uma breve historicização do funk}

Sucesso em bailes e rádios do Rio de Janeiro nos anos 1970 com sonoridades e letras norte-americanas, o funk começou a flertar com uma versão brasileira na década seguinte (ESSINGER, 2005). De acordo com Vianna (1987), apesar da popularização crescente na capital fluminense, com direito a bailes frequentados por milhares de jovens a cada fim de semana, o gênero ainda era retratado pela imprensa como uma "novidade" na época.

Nos anos 1990, o funk já era sinônimo de funk carioca no Rio de Janeiro e em todo o Brasil. Os artistas ligados ao gênero arrastavam multidões com letras em português que retratavam questões relativas ao cotidiano de favelas e bairros da periferia da cidade. Ao longo da década, as representações do funk na mídia se intensificaram, sendo marcadas por uma forte associação com a violência (HERSCHMANN, 2000). 
No entanto, o discurso dessa mesma mídia assentou as bases para momentos de glamourização do gênero, que ganhou espaço também nas seções culturais de grandes veículos de comunicação do país (HERSCHMANN, 2000).

Atualmente, o funk convive simultaneamente com estigmas associados à violência - bailes ainda são proibidos em diversas comunidades cariocas, por exemplo - e com um momento de ascensão na mídia e no cenário cultural contemporâneo ${ }^{6}$, circulando em espaços distintos de seus bailes de origem, como casas noturnas de classe média, academias, novelas da Rede Globo (PEREIRA DE SÁ, 2007) e peças publicitárias de empresas globais, foco do nosso artigo.

Nesse sentido, destacamos que, apesar do sucesso de alguns artistas e da projeção internacional do funk, a estrutura de produção e divulgação, sobretudo de novos artistas, ainda está longe do padrão relativo a revelações de outros gêneros musicais. Diante do pouco espaço nas mídias "tradicionais", o YouTube se tornou um elemento ainda mais central na estratégia de lançamento de artistas e produtores. Ao longo dos anos, a popularização na plataforma acompanhou um movimento de diversificação do gênero em vertentes como funk $p o p^{7}$ e funk ostentação ${ }^{8}$, com artistas de diferentes estilos emplacando hits no portal de vídeos. Foi o caso de MC Romântico e "As novinhas tão sensacional", música que acabou sendo apropriada pela marca McDonald's.

Tal apropriação, como discutiremos, gerou uma série de comentários entre os consumidores, muitos dos quais traziam claros embates e agressões simbólico-discursivas relacionados ao funk, à identidade da marca

6 Embora muitas dessas narrativas ainda sejam caracterizadas por juízos de valor que denotam uma visão preconceituosa, acreditamos que elas podem produzir "frestas" através das quais as diferenças podem emergir (HERSCHMANN, 2000).

7 Resultante da aproximação entre o funk e a música pop, o termo funk pop se refere a uma vertente reconhecida pelas letras que se distanciam do politicamente incorreto e pela sonoridade que mistura elementos da música pop com a batida do "tamborzão", que passou a dominar as músicas de funk produzidas no século XXI.

8 Vertente caracterizada pela exaltação ao consumo de bens de luxo, o funk ostentação se popularizou a partir da Baixada Santista (SP) em meados dos anos 2010 e influenciou inclusive outros gêneros musicais, como o sertanejo - alguns artistas passaram a se apresentar como representantes do "sertanejo ostentação". 
e, consciente ou inconscientemente, às suas próprias identidades, atreladas à esfera do consumo.

\section{Consumo e identidade nas mídias digitais}

Entendemos, em consonância com outros autores, que, no contexto do surgimento da Modernidade, relacionado ao declínio de referenciais sociais "fixos" como a igreja ou a escola (HALL, 2000), o consumo passou a constituir uma categoria central na definição da(s) identidade(s) dos sujeitos contemporâneos (BARBOSA e CAMPBELL, 2007; FEATHERSTONE, 1997). Nesse sentido, ele é uma ferramenta importante para "propiciar a significância e a identidade que os seres humanos modernos tanto desejam" (CAMPBELL, 2007, p. 63), ajudando os indivíduos a "descobrir quem são" e, dessa forma, combatendo "seu senso de insegurança ontológica” (CAMPBELL, 2007, p. 64), ainda que, conforme aponta Giddens (1991), a "obrigatoriedade" de escolhas cotidianas possa levar a crises de ansiedade.

Ainda de acordo com Campbell, esse processo de "descoberta" ou constituição de processos identitários propiciados pelo consumo está em permanente reconstrução e ressignificação. O próprio lugar do consumo no tecido social contemporâneo contribui para a construção de identidades mais "flexíveis" - afinal, trata-se de uma instância engendrada em um sistema complexo de significações culturais de valores instáveis?

Profundamente marcado pela autorreflexividade (GIDDENS, 1991), o processo de elaboração contínua da identidade por meio de consumo se torna ainda mais notável com o desenvolvimento das tecnologias de informação e comunicação, particularmente de espaços voltados à expressão e sociabilidade, como os sites de redes sociais, nos quais ficam visíveis e, até certo ponto, acessíveis as construções identitárias que os atores sociais buscam fazer de si (POLIVANOV, 2012).

9 Cabe destacar, entretanto, que concordamos com Barbosa e Campbell (2007, p. 24) no argumento de que tal fenômeno não representa o "fim do social"; fatores como cidadania, filiação religiosa, tradição e desempenho individual continuam a ter papel importante "na demarcação de fronteiras entre grupos" e na "construção de identidades". 
Plataformas como os sites de redes sociais são, desse modo, espaços profícuos para esse tipo de manifestação, uma vez que oferecem aos sujeitos a oportunidade de escolher tornar alguns conteúdos relacionados à imagem que desejam construir de si visíveis e outros, não (POLIVANOV, 2012), demonstrando sua afiliação ou rejeição a certos produtos de consumo - sejam bens tangíveis ou intangíveis, como serviços e mesmo ideias. Embora o YouTube não seja necessariamente um site de rede social estruturado para tal (RECUERO, 2009), consideramos as falas dos atores sociais no espaço dos comentários como performances discursivas que podem estar diretamente atreladas aos modos como esses sujeitos se apresentam aos demais nesse espaço. Além disso, a plataforma apresenta funcionalidades que tornam visíveis os canais seguidos pelos perfis individuais, apropriação que evidencia a construção de uma rede social e que não exploraremos neste artigo.

Assim, em um cenário no qual bens de consumo, sobretudo midiáticos, são, muitas vezes, mais acionados do que marcadores identitários "tradicionais", elementos como as preferências musicais, televisivas e mesmo alimentícias se tornam instrumentos de afiliação relevantes para a forma como os indivíduos nesses espaços desejam se apresentar aos demais que fazem parte de suas redes. E, cabe destacar, tal processo vale não apenas para indivíduos, mas também para as marcas. Ao tomar como inspiração uma música do chamado "funk putaria" para criar a peça publicitária de divulgação de seus novos sabores de sanduíche e batata frita, o McDonald's deixa, a nosso ver, clara a intenção de reforçar uma visão hedonista do consumo, segundo a qual o mesmo deve ser fonte de prazer e realização. ${ }^{10}$ De acordo com Rocha (2009), o viés hedonista, comum no discurso publicitário, relaciona o consumo infinito de bens a um sentimento perene de felicidade, o que, para o autor, se configura como um enquadramento superficial do fenômeno.

Em um release sobre o lançamento da primeira campanha, em outubro de 2015, o vice-presidente de marketing da rede no Brasil, Roberto

10 Também o fazem visando a um público específico, os jovens, por si só atrelados à esfera do entretenimento e da diversão, como apontam, por exemplo, Pereira e Polivanov (2012). 
Gnypek, afirma que "cheddar é o nosso produto ícone de sabor, prazer e indulgência que se conecta diretamente com o funk que é diversão, entretenimento e prazer sem limites" ("OS NOVINHOS ESTÃO DE PARABÉNS”, 2015). Ao refletir sobre a escolha da marca por um funk de conteúdo erotizado, cuja vertente "putaria”, com diversos palavrões, faz sucesso nos bailes e na internet, é possível pensar em uma dupla associação em relação ao "prazer sem limites" proposto pela franquia de alimentação.

Nesse sentido, destacamos a relevância da publicidade enquanto um sistema classificatório relacionado ao consumo por meio do qual se dá o compartilhamento e a classificação social de produtos e serviços como "necessidades", com certos valores atrelados a eles (ROCHA, 2009). Pode-se pensar, a partir dessa lógica, que a potência expressiva trazida pelas mídias digitais ${ }^{11}$ fornece instrumentos ainda mais amplos para o compartilhamento desse sistema cultural - inclusive para a problematização do mesmo.

Se considerarmos o histórico de estigmatização do funk no Brasil, a escolha do gênero para uma campanha publicitária, sobretudo com uma música de teor politicamente incorreto, seria improvável há alguns anos. Embora não seja o propósito deste artigo dissecar os múltiplos processos sociais e econômicos que inspiraram essa mudança, acreditamos que a pluralidade de vídeos de funk que se tornaram hits do YouTube recentemente (como "As novinhas tão sensacional") pode ter papel relevante para legitimar a criação da campanha, assim como outras apropriações do gênero em peças publicitárias. ${ }^{12}$ Assim, as práticas populares no "sistema cultural" (BURGUESS e GREEN, 2009) estabelecido na plataforma ganham relevância no conjunto de práticas sociais correntes que contribuem para que os valores em torno de determinados bens de consumo sejam ressignificados ao longo do tempo.

11 Em que pese a potência das mídias digitais, é preciso ressaltar a desigualdade no acesso e nas formas de utilização desses espaços, nos quais os atores sociais disputam lugares de visibilidade e autoridade (RECUERO, 2009), entre outros.

12 Ainda que essa estratégia nem sempre seja isenta de conflitos intensos, como ocorreu na supracitada campanha da Mercedes-Benz. 
Ao utilizar os bens para tornar visível "um conjunto de processos fluidos para classificar pessoas e eventos" (DOUGLAS e ISHERWOOD, 2009, p. 36), o consumo também atua como marcador cultural, construindo um universo compartilhado de valores e práticas. Entretanto, assim como os limites que Hall (2000) aponta para as construções identitárias mais "flexíveis" na contemporaneidade, a constituição do consumo enquanto marcador cultural também é atravessada por questões relacionadas a classe social, etnia e gênero.

Nessa direção, Barbosa e Campbell destacam a existência de uma hierarquização de bens que torna o consumo de determinados produtos e serviços mais lícito e desejável que o de outros. De acordo com os autores, embora essa classificação seja contextual, "existem significados culturais cristalizados sobre determinados bens e práticas sociais que transcendem alguns contextos" (BARBOSA e CAMPBELL, 2007, p. 39). No caso do funk, a ligação com a população pobre e negra das periferias permanece como um estigma (EVANGELISTA CUNHA, 2014) que aciona mecanismos de distinção (BOURDIEU, 1979) segundo os quais o gênero se torna inferior, assim como aquele que o consome.

Embora a peça publicitária do McDonald's possa ser considerada um exemplo de sucesso por sua popularidade, esse cruzamento entre produtos de diferentes esferas de consumo traz problematizações que contribuem para a reconfiguração de disputas simbólicas associadas a preconceitos e hierarquizações que ainda resistem no Brasil. Trata-se de pensar em que medida a legitimação oferecida pela campanha do McDonald's pode ser encarada como uma "artimanha discursiva" (ENNE, 2004, p. 113) que "higieniza" o funk e, por conseguinte, permite a expressão de discursos que defendem a música. Como veremos adiante, esse processo de apropriação do funk pela marca não é isento de conflitos, mas, ao contrário do que ocorre frequentemente em páginas com vídeos de funk populares, há poucos registros de rejeição ao jingle da campanha. 


\section{Disputas simbólico-discursivas sobre Novinhos Cheddar}

Criada pela agência DPZ\&T, a campanha Novinhos Cheddar tinha como objetivo apresentar duas novas versões do sanduíche Cheddar McMelt (item fixo no cardápio da rede): Grand Cheddar McMelt e Super Cheddar Bacon, além das McFritas Cheddar Bacon. Após serem comercializados em caráter temporário entre outubro e dezembro de 2015, os itens voltaram a ser vendidos entre agosto e setembro de 2016, também em caráter temporário. Com filmes publicitários, vinheta, material impresso e peças digitais para os canais da marca em sites de redes sociais, o projeto utilizou como carro-chefe uma paródia da música "As novinha tão sensacional", sucesso de MC Romântico lançado em 2014, para destacar os sabores "novinhos"13 e o "exagero" de cheddar nas receitas.

A música "As novinhas tão sensacional" surgiu no fim de 2013 no estúdio do DJ Bambam em Vaz Lobo, no subúrbio do Rio de Janeiro. Gravada com uma letra improvisada em 10 minutos por MC Romântico, a canção mistura a sonoridade tradicional do funk no século XXI com a "pegada" do reggaeton em uma vertente do funk que tem sido denominada de "rasterinha". Em entrevista ao canal Thump da publicação Vice (ROMANI, 2015), Romântico afirmou que a música obteve sucesso quase imediato nos canais do DJ Bambam em sites de redes sociais e, logo em seguida, "explodiu" nos bailes de funk. A letra é marcada por palavrões e palavras consideradas de baixo calão: "As novinha tão sensacional / Descendo com a xota prendendo no pau / Subindo com a xota prendendo no pau / Rebola com a xota prendendo no pau / Isso aqui tá gostoso, tá sensacional”. Com o sucesso, vieram os convites para as rádios e uma versão mais politicamente correta da música, mas, ainda assim, marcada pela forte erotização: "As novinha tão sensacional / Descendo gostosa, prendendo legal / Subindo gostosa, prendendo legal / Rebola gostosa, prendendo legal / Isso aqui tá gostoso, tá sensacional".

13 A popularização do termo "novinha” no funk pode ser comparada ao seu uso brega recifense, conforme descrito por Soares: "A novinha é o eco da ninfeta, da lolita, a menina jovem e sedutora, sexualmente voraz e apta a convocar o homem para a noite de sexo” (SOARES, 2010, p. 57). 
Na versão da campanha do McDonald's, a letra é alterada para mencionar os lançamentos da marca, mas a estrutura em uma única estrofe e a sonoridade permanecem semelhantes: "Os novinhos tão de parabéns / Os novinhos tão de parabéns / É o dobro de cheddar / Acabou de voltar / É cheddar mais bacon, pode relembrar / Batata com cheddar você vai pirar / Derretendo de novo / É só comemorar". O jingle é cantado por um intérprete cuja voz de jovem exagera no sotaque carioca, explicitando ainda mais a conexão com a música de MC Romântico. Seguindo outras propagandas recentes relacionadas à marca, a campanha em vídeo apresenta uma narrativa simples, com foco nos ingredientes e na preparação dos sanduíches e da batata.

A audiência do comercial de lançamento da campanha Novinhos Cheddar, veiculada durante outubro e dezembro de 2015, já comprovava o sucesso da empreitada: até maio de 2016, o vídeo somava pouco mais de 607 mil visualizações no YouTube. Com o retorno da campanha, em agosto de 2016, foi possível constatar que o comercial e, provavelmente, os produtos anunciados caíram no gosto do público. Até abril de 2017, o vídeo intitulado "Os \#NovinhosCheddar estão no McDonald's. De novo!” somava mais de 6,7 milhões de visualizações na página oficial do McDonald's Brasil no YouTube, número muito superior às visualizações dos demais vídeos postados no mesmo canal. No período analisado, entre setembro de 2016 e abril de 2017, a peça recebeu 978 comentários e números expressivos de aprovação: foram 15.398 "gostei” e apenas 4.053 "não gostei” registrados na página. A aprovação do uso da música na campanha se torna ainda mais evidente com a publicação de um vídeo de lmin40s com a "versão estendida" da música ${ }^{14}$ pelo usuário jhonatan jh apenas dois dias após o lançamento da campanha no canal da marca no YouTube. Posteriormente, o vídeo de $1 \min 40$ s foi deletado.

Em uma análise qualitativa exploratória, selecionamos 40 comentários entre os classificados pelo sistema do YouTube como mais relevantes

14 Com $1 \min 40$ s, a "versão estendida” apresenta apenas uma repetição do jingle. Disponível em: https://www.youtube.com/watch?v=yH9TNQG-AwM. Acesso em: mai. 2017. 
nas 10 primeiras páginas de comentários sobre a campanha no canal oficial do McDonald's na plataforma. As falas mencionam o jingle explicitamente e a amostra inclui respostas a esses comentários ${ }^{15}$.

Uma primeira análise sobre os comentários postados na página do vídeo revela que a maioria do público que optou por se manifestar no espaço aprovou o uso do funk na campanha: são recorrentes frases como "não consigo tirar a música da cabeça" e "comercial viciante".

Figuras 1, 2 e 3 - Comentários elogiosos ao jingle da campanha do McDonald's.

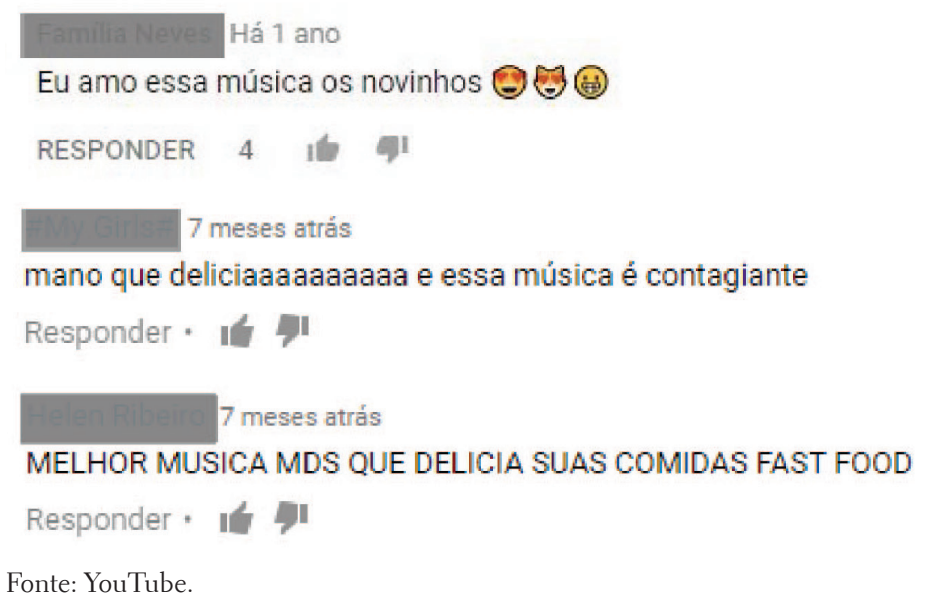

A música popular massiva é marcada, entre outros aspectos, por ser considerada comercial, claramente voltada para fins mercadológicos de venda (FRITH, 2004), e por essa capacidade de ser - até certo ponto - facilmente reproduzível em termos de melodia, "fixando-se" na memória (ainda mais se pensarmos em gêneros como funk e pop). Os comentários elogiosos apontam claramente para essas características, que são, mais especificamente, traços associados a jingles publicitários que têm como intuito justamente chamar atenção dos consumidores e

15 Respostas a outros comentários dentro do universo analisado esporadicamente continham menções à música. Contudo, nosso objetivo foi manter o foco em discussões em torno da centralidade da música na campanha. 
“fixar" a mensagem em sua memória (ALLAN, 2006). Nesse sentido, tais comentários parecem indicar que a estratégia adotada pela marca tem funcionado.

Conforme exemplificamos nos comentários da Figura 4, a relação entre o funk parodiado e a campanha publicitária foi reconhecida - positiva, negativa ou ironicamente - por boa parte do público: na página do videoclipe oficial de "As novinhas tão sensacional" e em uma das páginas com a versão original, retirada do ar pelo YouTube ${ }^{16}$ (provavelmente pelo conteúdo impróprio), havia diversos comentários que indicavam visitas provenientes de pessoas que se interessaram pela música a partir do jingle.

Figura 4 - Comentário registrado na página do videoclipe oficial de "As novinhas tão sensacional".

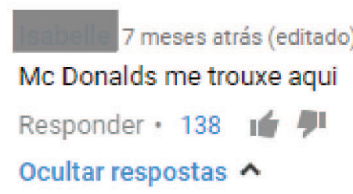

Fonte: YouTube.

Outra questão que merece destaque consiste no fato de que comentários na página do vídeo publicitário mencionam explicitamente a versão "proibida" da música, como ilustra a Figura 5:

Figura 5 - Comentário menciona funk que inspirou campanha.

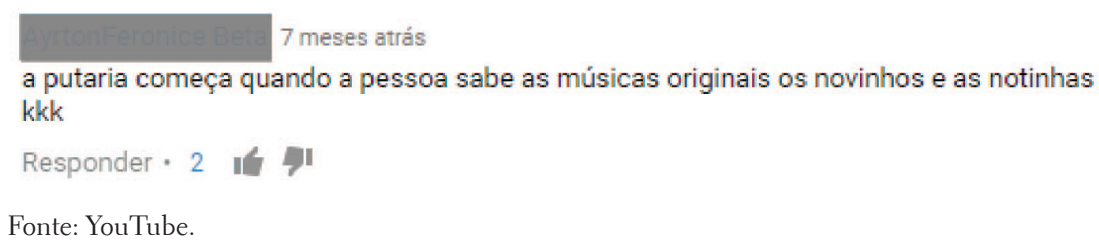

16 O vídeo em questão estava disponível no link https://www.youtube.com/watch?v=_AMvxIR_ Sf8. Em abril de 2017, data do último acesso ao endereço, o YouTube indicava que o mesmo fora retirado do ar. 
Assim como outras paródias associadas ao gênero (EVANGELISTA CUNHA, 2014), a campanha pode se enquadrar no que Felinto (2007) classifica como cultura do spoof, paródia ou imitação de um vídeo. Popular entre as práticas culturais que se consolidaram no YouTube, esse tipo de vídeo, que geralmente parodia outras produções disponíveis na própria plataforma de vídeos, tem sido largamente utilizado pelo marketing em outras mídias de modo a estabelecer uma conexão multiplataforma e conquistar sobretudo o público jovem. Assim, o formato do spoof pode ser entendido como um tipo de linguagem vinculado à "cultura remix" (LESSIG, 2008), que parte de determinado conteúdo para criar outro, potencializando, nesse caso, apropriações do funk para fins publicitários. ${ }^{17}$

Entretanto, quando o objeto da paródia é um gênero musical marcado por estigmas, tal apropriação ganha novas nuances. No caso do funk, existe um conflito entre o consumo do gênero e a rejeição a ele, já que, conforme lembra Hutcheon (2000), é preciso reconhecer o texto original para compreender a dimensão irônica da paródia. Dessa forma, a música, que é apontada por alguns como “degradante” na página do videoclipe original de "As novinhas tão sensacional" - cujas primeiras páginas de "comentários mais relevantes" apresentam diversas críticas, diferentemente da peça do McDonald's -, torna-se, para boa parte do público que aprovou a campanha \#Novinhos Cheddar, algo "viciante" e valorizado.

Contudo, como mostram os próximos comentários que compõem nosso corpus de pesquisa, parece haver limites para essa negociação de sentidos em relação ao funk. Segundo opiniões que poderiam ser classificadas como de antifãs ${ }^{18}$, a apropriação do gênero por parte do McDonald's é vista de forma negativa. De acordo com essa ótica, a

17 Outros trabalhos apontam que a relação entre spoof e publicidade pode estar atrelada a movimentos como culture jamming, "conjunto de técnicas de intervenção que alteram e subvertem os símbolos comerciais impostos pelo marketing das grandes empresas por meio da publicidade" (OLIVEIRA e PESSOA, 2014, p. 5).

18 Segundo Gray (2003), o antifã dedica-se a odiar alguma coisa a partir do momento em que a enxerga como um "perigo". No caso dos antifãs de funk que se manifestam na rede, existe uma percepção do gênero e de todo o universo que o cerca como uma ameaça a outros gêneros, sobretudo para o rock. 
Figura 6 - Comentários valorizam jingle da campanha.

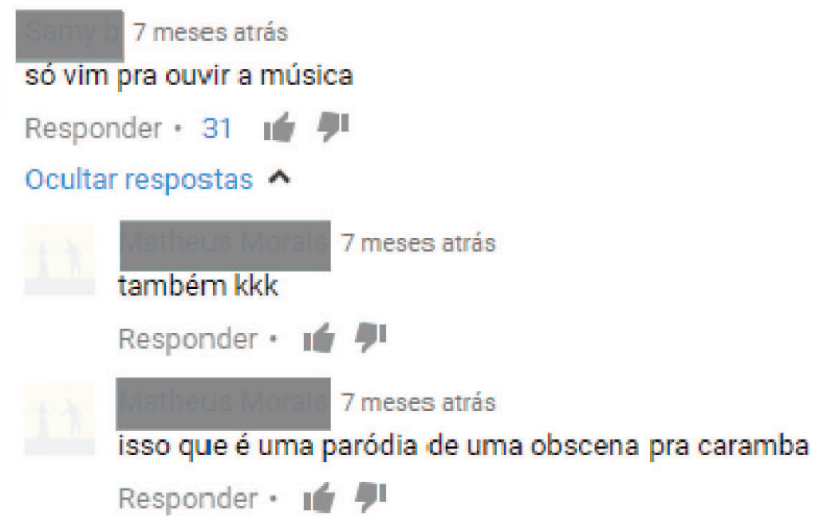

Fonte: YouTube.

repercussão positiva da campanha seria mais um atestado de que o funk é uma "ameaça" para a sociedade brasileira, abordagem que reflete uma série de preconceitos associados ao histórico do gênero. Destaca-se, porém, que apenas dois entre os 40 comentários refletem essa postura e que, em um deles, apresentado na Figura 7 , a escolha da marca foi prontamente defendida em discursos que legitimam o funk como gênero ("Funk é expressão musical. Aceita que dói menos") ou, ao menos, concordam com a escolha da marca ("também odeio funk, mas essa música e legal").

Figuras 7 e 8 - Comentários criticam uso de funk em campanha publicitária.

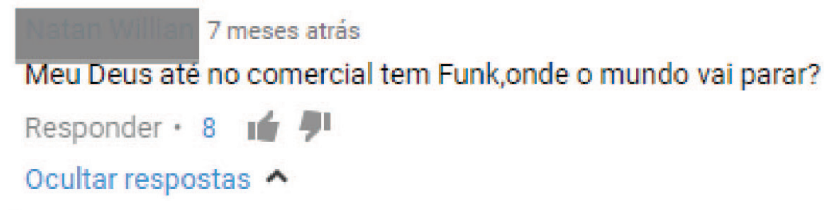

8 meses atrás

Eu sempre pergunto quando o Super Cheddar Bacon volta! Eu sonhei com esse dia. A única coisa que tirou minha fome foi esse funk.

Responder .

Fonte: YouTube. 
Além das respostas em defesa da música nesses mesmos comentários, há comentários "soltos" que criticam comentários negativos explicitamente, como na Figura 9. Seriam, portanto, possíveis indícios da existência de outros discursos que não aparecem no corpus deste trabalho. Outro ponto importante é que, devido às limitações da metodologia adotada, não é possível saber se esses indivíduos são admiradores do gênero ou da marca e de seus produtos. ${ }^{19}$ No entanto, podemos inferir que mostram algum tipo de simpatia pela escolha do funk como trilha sonora para a campanha.

Figura 9 - Usuário defende uso de funk na campanha Novinhos Cheddar.

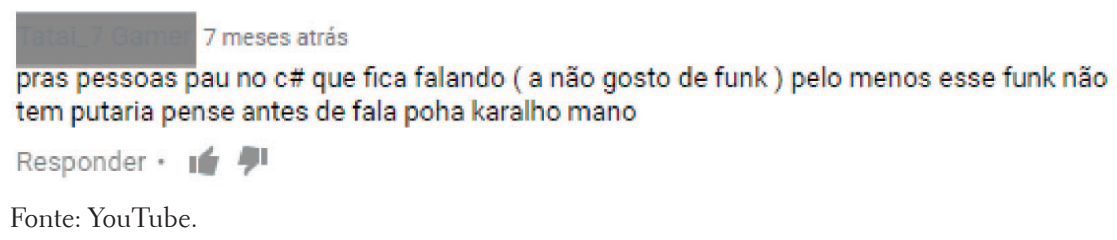

Fonte: YouTube.

Tais expressões, tanto de suporte quanto de rejeição à utilização da canção, podem ser entendidas como performances discursivas dos sujeitos, que visam explicitar suas afiliações a determinados valores, gêneros musicais (no caso, o funk) e marcas (McDonald's). Estes atuam como marcadores de suas identidades, conforme discutimos anteriormente, e nos remetem à noção de "comunidades emocionais" (FREIRE FILHO, 2013). É possível tomar a defesa da campanha Novinhos Cheddar como uma possível manifestação da relação de proximidade entre a marca e parte de seus consumidores capaz de neutralizar eventuais críticas à adaptação de um funk "putaria" para a trilha sonora. Conforme explica Freire Filho, a gramática das emoções de determinada sociedade é moldada "por hierarquias sociais e por relações cotidianas de poder" (FREIRE FILHO, 2013, p. 4). Fortemente influenciadas pela mídia,

19 Também não é possível saber se esses defensores não são pessoas contratadas pelo próprio McDonald's para defender a marca. 
tais leituras, que variam de acordo com condições socioeconômicas, status, idade e gênero, moldam comunidades emocionais pautadas por sentimentos como amor, ódio ou raiva.

Nesse sentido, cabe destacar o esforço de marcas e organizações para a construção de capital emocional (JENKINS, 2010) a partir de diferentes estratégias em plataformas digitais. Em um cenário em que múltiplas possibilidades de interação com os consumidores são disponibilizadas ao mercado, busca-se fomentar a consolidação de um tipo de agente "ao qual interessa o envolvimento mais pessoal e direto com o intangível da marca em questão" (CASTRO, 2012, p. 136). Trata-se, assim, de empreitadas que visam ao desenvolvimento de relações afetivas com o objetivo de transformar clientes em fãs. Frequentemente, esses fãs se reúnem em comunidades de marca, onde é possível se filiar a determinado estilo de vida que "enriquece as experiências de troca com parceiros similares e com a empresa em si” (ALMEIDA et al., 2011, p. 370). Com cerca de 73 milhões de "curtidas" em sua página oficial no Facebook em outubro de 2017, pode-se dizer que o McDonald's reúne extensa comunidade de fãs (embora, ressaltemos, não seja possível afirmar que todos os indivíduos que curtem a página são, efetivamente, fãs da empresa).

Para além da admiração à marca, contudo, retomamos o nosso argumento acerca da "higienização" do funk na paródia da multinacional. Ao realizar uma tentativa de apagar determinadas características que reforçam a conexão da música com as comunidades de origem do funk, a marca evita acionar a extensa comunidade de antifãs do gênero, cujas críticas muitas vezes demonstram, de modo explícito, o ódio também às ideias sobre periferia ali representadas. Dessa forma, apesar de manter a referência ao funk original, o comercial apresenta: a) sonoridade mais pop; b) letra modificada; c) substituição dos corpos negros dos "novinhos" (cantor e dançarinas) que aparecem no videoclipe da música pelo foco exclusivo no preparo dos alimentos promovidos.

Quanto ao primeiro ponto, há, na peça do McDonald's, um enfraquecimento sonoro de uma marca do funk: a batida forte, ou "batidão" (ESSINGER, 2005), com graves muito potentes. Em contrapartida, 
ocorre a inclusão de sons melódicos produzidos por sintetizadores ou teclados e o uso de vocais afinados, muito possivelmente editados em estúdio, elementos frequentemente ligados a uma estética sonora do pop (FRITH, 2004), ainda que seja difícil delimitála. Quanto à letra, conforme apontamos, há modificações consideráveis. Embora mantenha o tom informal do funk ("As novinhas tão sensacional"/"Os novinhos tão de parabéns"), o erro de concordância é suprimido. Enquanto a letra da primeira versão de \#NovinhosCheddar, veiculada em 2015, fazia referências um pouco mais diretas à sensualidade da música original, com termos como "pegando geral" e "derretendo gostoso, é fenomenal", ${ }^{20} \mathrm{a}$ campanha de 2016 promove uma neutralização maior da mensagem. Pode-se argumentar que, neste último caso, o principal e quiçá único elo explícito entre a canção original e o jingle, no que se refere a esse campo hermenêutico, é a evocação às/aos novinhas/os: no primeiro caso, as jovens e sedutoras meninas; no segundo, os novos sabores do hambúrguer e das fritas. Tal evocação não se repete no plano imagético, uma vez que, conforme explicitamos, o comercial retira os indivíduos e o cenário urbano periférico do clipe original em prol de um cenário asséptico com os produtos emoldurados por cores neutras de fundo.

A partir do material analisado, defendemos que essas mudanças são parte importante da aceitação da campanha. Apesar de manter a associação com o funk original para que o público compreenda que se trata de uma paródia, o vídeo trata de eliminar elementos relacionados aos estigmas em torno do funk - e, portanto, aos processos distintivos associados ao seu consumo ou à sua rejeição.

Considerando o papel da publicidade no processo social de articulação de sentidos, a visibilidade conferida pela campanha poderia representar uma oportunidade para discutir preconceitos remanescentes atrelados ao funk. Pelo que pudemos constatar nos comentários analisados, de fato houve algum debate, mas tais colocações podem ser consideradas, sobretudo, como "efeito colateral" da referência ao gênero. De acordo

20 Letra completa: "Dobro de cheddar pegando geral / É cheddar mais bacon ficou genial / Batata com cheddar não tem nada igual / Derretendo gostoso, fenomenal”. 
com a abordagem do McDonald's, o consumo do funk é desejável a partir de determinados parâmetros, como o uso de recursos paródicos e a "higienização", legitimando escolhas que mantêm mecanismos de distinção relacionados ao processo de estigmatização do gênero.

Tais estratégias também parecem estar intimamente ligadas aos comentários elogiosos na página da campanha, que fazem parte de uma expressão identitária - tanto da marca quanto dos consumidores - mais aceita socialmente. Isto é, a partir do momento em que se "limpam" as marcas estigmatizadas do funk da peça publicitária, os atores sociais se sentem mais confortáveis para expressar sua filiação à mesma. Afinal, é na esfera do consumo que construímos (e reconstruímos) nossas identidades continuamente e é a partir dos bens, ideias e produtos "organizados" no campo da publicidade que nos afiliamos a determinados valores.

\section{Considerações finais}

Ao longo deste trabalho, procuramos destacar alguns elementos que problematizam a apropriação de um gênero musical periférico como o funk na campanha publicitária \#Novinhos Cheddar. Interessou-nos particularmente a reflexão sobre os atravessamentos em relação ao consumo de produtos alimentícios e gêneros musicais no ambiente dos sites de redes sociais, onde a relação entre consumo e identidade se torna ainda mais evidente diante das possibilidades de autoconstrução identitária nesses espaços. A partir do momento em que construções identitárias também são pautadas por esse consumo e que plataformas como o YouTube o tornam cada vez mais visível por meio de diversas funcionalidades (número de visualizações, "gostei" e comentários, por exemplo), o sistema classificatório que o permeia torna-se ainda mais passível de debates e de disputas simbólicas envolvendo marcas e sujeitos "comuns".

Pontuamos também que o objeto de pesquisa suscita reflexões sobre o uso de gêneros musicais periféricos como elementos de sound branding, recurso pelo qual a filosofia da marca é traduzida de forma acústica (GUERRA, 2013). No caso do McDonald's, uma marca notável pelo 
consumo por parte do público jovem, o recurso paródico, aliado a uma música já conhecida e relacionada à diversão, parece ter sido usado para reforçar a conexão emocional dos consumidores com a própria marca e seus valores.

Entretanto, como buscamos ressaltar, trata-se de uma apropriação que: 1) não elimina os conflitos relacionados às disputas simbólicas entre os diferentes atores sociais em contato por meio de plataformas digitais; e 2) é feita de forma a apagar certos marcadores relevantes do universo do funk, como os jovens negros, o uso de linguagem coloquial e as favelas, por exemplo, "higienizando-o". Os debates suscitados em relação ao uso de uma música cujo teor original é considerado "inapropriado” e que está associada a um histórico de marginalização em uma campanha publicitária evidenciam, assim, o papel central do consumo como elemento instável por meio do qual valores podem ser ressignificados. Trata-se de um complexo sistema que, assim como as identidades na contemporaneidade, atua entre as potências do imaginário e de limitações sociais. Limitações essas cujas fronteiras são problematizadas, ainda que de forma não intencional, por campanhas como \#Novinhos Cheddar.

\section{Referências}

ALLAN, D. Effects of popular music on attention and memory in advertising. Journal of Advertising Research, v. 46, n. 4, p. 434-444, 2006.

ALMEIDA, S. O.; MAZZON, J. A.; DHOLAKIA, U. M.; MÜLLER NETO, H. F. Os efeitos da participação em comunidades virtuais de marca no comportamento do consumidor: proposição e teste de um modelo teórico. RAC. Revista de Administração Contemporânea, v. 15, p. 366-391, 2011.

BARBOSA, L.; CAMPBELL, C. (Orgs.). Cultura, consumo e identidade. Rio de Janeiro: FGV, 2007.

BOURDIEU, P. A distinção: crítica social do julgamento. 5. ed. São Paulo: Edusp, 2008. 
CAMPBELL, C. Eu compro, logo sei que existo: as bases metafísicas do consumo moderno. In: BARBOSA, L.; CAMPBELL, C. (Orgs.). Cultura, consumo e identidade. Rio de Janeiro: FGV, 2007. p. 47-64.

CASTRO, G. Entretenimento, sociabilidade e consumo nas redes sociais: cativando o consumidor-fã. In: COMUNICON, 1., 2011, São Paulo. Anais... São Paulo: Escola Superior e Propaganda e Marketing, 2011.

DOUGLAS, M.; ISHERWOOD, B. O mundo dos bens: para uma antropologia do consumo. Rio de Janeiro: UFRJ, 2009.

ENNE, A. "E daí?", "pronto, falei!", "confesso": artimanhas discursivas de qualificação e desqualificação do gosto e da distinção. PragMATIZES - Revista Latino-americana de Estudos em Cultura, v. 4, n. 6, 2014.

ESSINGER, S. Batidão: uma história do funk. Rio de Janeiro: Record, 2005.

EVANGELISTA CUNHA, S. "É som de preto, de favelado!": gosto e disputas simbólicas em torno do funk no YouTube. 2014. 122f. Dissertação (mestrado em Comunicação) - Programa de Pós-Graduação em Comunicação da Universidade Federal Fluminense, Niterói, 2014.

FACINA, A. Eu só quero ser feliz: quem é a juventude funkeira no Rio de Janeiro? Revista EPOS - genealogia, subjetivações e violências, v. 1, n. 2, 2010.

FEATHERSTONE, M. Cultura de consumo e pós-modernismo. São Paulo: Studio Nobel, 1995.

FELINTO, E. Videotrash: o YouTube e a cultura do "spoof” na Internet. In: ENCONTRO DA COMPÓS, XVI, 2007, Curitiba. Anais... Curitiba: Compós, 2007.

FREIRE FILHO, J. A comunicação passional dos fãs: expressões de amor e de ódio nas redes sociais. In: CONGRESSO BRASILEIRO DE CIÊNCIAS DA COMUNICAÇÃO, XXXVI, 2013, Manaus. Anais... Manaus: Intercom, 2013. Disponível em: http://www.intercom.org.br/papers/nacionais/2013/resumos/R8-2085-l.pdf. Acesso em: 13 abr. 2016.

FRITH, S. Popular Music: music and identity. EUA; Canadá: Routledge, 2004.

GALO, A. Novinhos Cheddar. Música estendida. [s. 1.], 2016. Disponível em: https:// www.youtube.com/watch?v=y909R4y8Hgg\&t=7s. Acesso em: jan. 2017.

GIDDENS, A. Modernidade e identidade. São Paulo: Unesp, 1991.

. Sociologia. Porto Alegre: Artmed, 2012.

GRAY, J. New audiences, new textualities: antifans and non-fans. International Journal of Cultural Studies, Londres, p. 64-81, 2003.

GUERRA, G. Music branding: qual o som da sua marca? Rio de Janeiro: Elsevier, 2013. HALL, S. A identidade cultural na pós-modernidade. Rio de Janeiro. DP\&A, 2000.

HERSCHMANN, M. As imagens das galeras funk na imprensa. In: PEREIRA, C. et al (Orgs.). Linguagens da violência. Rio de Janeiro: Rocco, 2000. p. 97-106.

JENKINS, H. Cultura da convergência. São Paulo: Aleph, 2010.

LESSIG, L. Remix: Making Art and Commerce Thrive in the Hybrid Economy. Nova York: Penguin, 2008. 
LOPES, A. Funk-se quem quiser. No batidão negro da cidade carioca. 2010. 187f. Tese (doutorado em Linguística) - Programa de Pós-Graduação em Linguística, Universidade Estadual de Campinas, Campinas, 2010.

MCDONALD'S Brasil. Página oficial no Facebook. Disponível em: https://www.facebook.com/McDonaldsBrasil. Acesso em: abr. 2017.

MC ROMÂNTICO. As novinhas tão sensacional. Clipe oficial. Rio de Janeiro: Tom Produções, 2014. Disponível em: http://bit.ly/2tuwSHJ. Acesso em: jan. 2017.

MONTARDO, S; ARAÚJO, W. Performance e práticas de consumo online: ciberativismo em sites de redes sociais. Revista FAMECOS, v. 2, p. 472-494, 2013.

OLIVEIRA, R.; PESSÔA, L. Absolut spoof: subvertendo a publicidade da marca Absolut. Pensamento Contemporâneo em Administração, v. 8, n. 2, p. 1-16, 2014.

“OS NOVINHOS ESTÃO DE PARABÉNS” no McDonald's. Propmark, 20 out. 2015.

Disponível em: http://propmark.com.br/anunciantes/os-novinhos-estao-de-parabens-no-mcdonalds. Acesso em: set. 2016.

OS \#NOVINHOSCHEDDAR ESTÃO NO MCDONALD'S. De novo! YouTube, 29 ago. 2016. Disponível em: https://www.youtube.com/watch?v=JzoAAm3liqA. Acesso em: jan. 2017.

PEREIRA, V.; POLIVANOV, B. Entretenimento como linguagem e materialidades dos meios nas relações de jovens e tecnologias contemporâneas. In: BARBOSA, L. (Org.). Juventude e gerações no Brasil contemporâneo. Porto Alegre: Sulina, 2012. p. 76-94.

PEREIRA DE SÁ, S. Funk carioca: música eletrônica popular brasileira?! E-Compós, v. 10, p. 1-18, 2007.

.; EVANGELISTA CUNHA, S. Controvérsias do funk no YouTube: o caso do Passinho do Volante. ECO-Pós, Rio de Janeiro, v. 17, n. 3, p. 1-14, 2014.

POLIVANOV, B. Dinâmicas identitárias em sites de redes sociais: estudo com participantes de cenas de música eletrônica no Facebook. Rio de Janeiro: Multifoco, 2014.

RECUERO, R. Redes sociais na internet. Porto Alegre: Sulina, 2009.

ROCHA, E. Os bens como cultura: Mary Douglas e a antropologia do consumo. In: DOUGLAS, M.; ISHERWOOD, B. O mundo dos bens: para uma antropologia do consumo. Rio de Janeiro: UFRJ, 2009. p. 7-18.

ROMANI, B. Por que o McDonald's usou um funk putaria para vender seu mais novo sanduíche? Vice, 26 nov. 2015. Disponível em: http://bit.ly/2usgXGY. Acesso em: abr. 2017.

SOARES, T. Conveniências performáticas num show de brega no Recife: espaços sexualizados e desejos deslizantes de piriguetes e cafuçus. Logos, v. 19, n. 1, p. 55-67, 2012.

TROTTA, F. A música que incomoda: o funk e o rolezinho. In: ENCONTRO DA COMPÓS, XXIII, 2014, Belém. Anais... Belém: Compós, 2014.

TURLAO, F. Lelek Lek e Mercedes-Benz combinam? MeioŁMensagem, 4 abr. 2013.

Disponível em: http://www.meioemensagem.com.br/home/comunicacao/2013/04/04/ lelek-lek-e-mercedes-benz-combinam.html. Acesso em: jan. 2017.

VIANNA, H. O mundo funk carioca. Rio de Janeiro: Zahar, 1997. 


\section{Sobre as autoras}

Simone Evangelista Cunha - Professora substituta do Departamento de Estudos Culturais e Mídia da Universidade Federal Fluminense. Doutoranda do Programa de Pós-Graduação em Comunicação da Universidade Federal Fluminense. Mestre em Comunicação pelo mesmo programa.

Beatriz Brandão Polivanov - Professora adjunta e chefe do Departamento de Estudos Culturais e Mídia e professora permanente do Programa de Pós-Graduação em Comunicação da Universidade Federal Fluminense. Doutora e mestre em Comunicação pelo mesmo programa.

Data de submissão: 02/07/2017

Data de aceite: 19/09/2017 